\title{
Café Cul-de-Sac: Made Up Spaces
}

\author{
Michael Joyce
}

Looking back on it there seem four provisional principles of hypertext fiction which one ought to give no more credence to than to the scraps within fortune cookies. Yet in my memory they seem lost directions to a distant space, a café or cul-de-sac, tiny maps no longer legible, a pattern of ashes left after these miniscule scrolls have been sentimentally set aflame in a lover's ashtray.

1. The polygon is the figure of the flow of so-called liquid architecture. Its aspect is the uncornered corner, the twenty-faced die, the café, the locale which in The Coming Community Giorgio Agamben calls "the space of ease between everything and itself" (53). There the multiple story, the hypertext fiction, takes place, occupies itself in the double sense of marking time and living within a volume, in this case oneself. Not only is occupation doubled, but inhabitation is also-we are inhabited by the story which we in turn inhabit.

2. The hyperlink lacks form-it is the form of lacking. longing for form. There is never a single link and yet the succession of them is not itself something other than its spatio-temporal experience, a narrative which fools us into thinking it has a history we have forgotten, a surface whose trace, like Greg Lynn`s $H 2$ House, our passage discloses and erases in turn.

Michael Joyce is the author of numerous hypertext fictions, as well as a novel, Liam's Going (McPherson and Company, 2002), and a collection of short fictions and prose pieces, Moral Tales and Meditations: Technological Parables and Refractions (SUNY, 2001). He is currently Associate Professor of English at Vassar College. 
3. On the web at least every text is exo-skeletal, always outside itself as much as we are inside it. Yet its external being is transparent, more jellyfish than hermit crab, the without we are within. Nonetheless its "architecture of dissipative forces," to use Ben van Berkel's phrase, "can offer a pattern, a virtual form that is assembled as a generating multiple of complex field of forces" (657).

4. Hypertextuality shows itself in the unlinked, the cul-de-sac, the experience of being unfairly at an ending which is simultaneously not an ending, no place unless a place where one intends to be. We always alternate between backing away from the cul-de-sac, like Benjamin's angel of history, and setting forth from it, either as resident angels or the wayfarer refreshed, having found the place he set out for, a punctum which sits as a void in the grid, a droplet on the tree branches, the "space of higher dimensionality" which Brian Massumi suggests characterizes Lynn's blob space (Lynn, "Blobs").

So end the four principles and what follows is to be read in the light of the flame of their disappearance, a phrase which, written years ago, now inevitably takes on poignant and valedictory layers in the history we have read since both in actual cityscapes and their mediations. Yet no one reads anything, nothing one says lasts, not even the future. We live now in what Peter Lunenfeld has termed a permanent future. "If, from the turn of the century through the 1960s, futures were mapped out, painted, printed, filmed, animated, and even occasionally built," Lunenfeld writes, "today, the fever for what is yet to be has perceptibly cooled" and we are left with "a disappointment that the present has not lived up to the past's hopes for it."

The prototype for the networked city is the architectural palimpsest of the cityscape, a permanent future of style upon style, patterns on ash, the carving into and leaking out from, the eddies in which liquid architectures take on recurrent, pliant, and supple, if not persistent, forms.

It seems absurd of course on the face of it to claim that the city of text, whatever that may be, is an actual place we may inhabit or that it offers us the traditional solaces and stimulations - social engagement, psychological differentiation, economic opportunity, expanded commerce, spiritual and artistic expression, erotic variety, intellectual variation, political aggregation and action, and so on-which the "real" city does.

Yet as soon as we allow ourselves the gesture, so familiar now thirty plus years after 1968, of considering the real city to be socially constructed-as soon as we make the claim that different populations occupy different cities within the actual one by virtue of their interactions, their perceptions, and their status-then the city's being seems to depend less and less upon embodied presence and more upon the mediated story of its forms, whose unfolding, however paradoxically, depends upon the embodied reader and her utterances or silences.

As de Certeau suggests, "spatial order organizes an ensemble of possibilities ... and interdictions" which "the walker actualizes," making them "exist as well as emerge" (98). For de Certeau the walker does not merely move about the features of 
the city, but "he moves them about and he invents others, since the crossing, drifting away, or improvisations of walking privilege, transform, or abandon spatial elements" (98).

These elements take on the higher dimensionality which Massumi evokes in his claim vis-à-vis Lynn that "[i]f each independent variable constitutes a dimension, the blob space has five (circumference, mass, force of attraction, zone of fusion, zone of inflection )."

The latter three dimensions are literally incorporated within the reader, whose being is the ground upon which attraction plays, whose presence marks the zone of fusion, and whose utterance (given or retained) is the zone of inflection.

Under such circumstances embodied presence can threaten to become merely a quaintly sentimental custom as we begin to endow the virtual city with possibilities similar to those with which we endow the real city.

Cyberculture forces an urgency upon us in regard to differentiating between the real and the virtual insofar as our own reality and embodiment are intertwined with the spaces we think to inhabit. A virtual X, says Peter Skagestad, is "what you get when the information structure of X is detached from its physical structure." Architects know this exo-skeletal and detached form as program-writers see it as story. Since September 2001 the detachment of information from physical structure has inhabited our own bodies as well as our histories and cityscapes.

Again-perhaps forever now-we oscillate between detachments and attachments. My own attachment to the notion of the city of text goes back to a ten year old essay of mine, "A Memphite Topography: Governance and the City of Text" (Of Two Minds).

In that decade old text, in another century, I spoke of my interest in the city "as a place where language transforms us ... not merely in future tense, if you will, but future text" (106).

Back then I saw the text as a place of encounter where, like de Certeau's walker or Chris Marker's "story of a man marked by an image" in La Jetée, we continually, not to say endlessly, create the future.

I had in mind a textuality not unlike Marcos Novak's “intelligent paragraph" which for him performs "like an intelligent reader, constantly reinterpreting the whole text with each new word that is given . . . [altering] a number of internal, hypothetical models of what the paragraph, and the entire text might mean." For Novak intelligent texts offer "a point of departure for envisioning the potential of intelligent environments to communicate directly through the new medium of virtual space, without narrative, linearity, reward, or any other such teleological structure" (Mork).

Within an essay prophesying the data structure as "the preeminent medium of the new age," which given recent history now seems almost nostalgic in its benign melancholy, Richard Powers fancies "the future's supreme art form" as a virtual reality simulation of the city whose transportive jouissance ends in " $[\mathrm{t}]$ he sadness of consummation. The sadness of infinite freedom. Of save and reboot. Of having the world, in all its heft and bruise and particularity, go utterly your own way."

Infinite freedom is the space of cul-de-sac or café. As a continual future it lacks 
history but occupies experience. It is exo-skeletal, outside the body, virtual. In the mid '50s Joseph Frank's famous essay, "Spatial Form in Modern Literature," is already nostalgic for the end of history.

Frank's apprehension of what I have called storyspace is tantric, finding jouissance only in endlessly deferred gratification. "The meaning-relationship is completed only by the simultaneous perception in space of word-groups that have no comprehensible relation to each other when read consecutively in time." Frank says, "modern poetry asks its readers to suspend the process of individual reference temporarily until the entire pattern of internal references can be apprehended as a unity" (13).

But what are we to do when the whole never again presents itself, or presents itself as rhizomic, hybrid, fragmented? How do we read rhythms of fissure, disjuncture, linkage except as story spaces?

Frank's sense of suspended reference prefigures Lynn's claim that "stable architecture must be conceived in a time-based manner, but not exactly move, rather to conceptualize the dynamic which emerges as field-forms" ("Greg Lynn: An Advanced Form of Movement" 56).

Rem Koolhaas, too, finds hope in the exo-skeletal. "Through the double disconnection of lobotomy and schism-by separating exterior and interior architecture, and developing the latter in small autonomous installments," he writes, "such structures can devote their exteriors only to formalism and their interiors only to functionalism" (28).

In language which recalls Benjamin's sense of the arcades' "continuous shift of external and internal stimuli" (88), Koolhaas claims that such doubled spaces "not only resolve forever the conflict between form and function, but create a city where permanent monoliths celebrate metropolitan instability" (28).

Permanent monoliths to instability memorialize what Guy Debord calls "the derangement of the unchangeable order of the society" (128). This derangement results in what I have elsewhere called "changing change," a notion similar to what Novak means when he says, "we have entered a time when the invariance itself is rendered dynamic, when acceleration accelerates."

We celebrate instability by naming it. The names are stories. Undertaking a memorable walkthrough of an utterly virtual, cookie-cutter exurb in the mythological, proto-cyber Texas classic film True Stories, David Byrne says, "Things that never had names before now are easily described. It makes conversation easy." Byrne's town in the film-Virgil, Texas—-has a name which provides a locale, just as his narrator/developer character provides a persona, meant to evoke the Divine Comedy.

Novak's description of a liquid architecture could equally be taken as a description of Dante's method:

[A]n architecture whose form is contingent on the interests of the beholder . . . without doors and hallways, where the next room is always where it needs to be and what it needs to be ... . Liquid ... cities ... that change at the shift of a value, where visitors with different backgrounds see different landmarks, where neigh- 
borhoods vary with ideas held in common, and evolve as the ideas mature or dissolve. ("TransTerraFirma")

Through these neighborhoods the shortest distance is a network. Annette Loudon amplifies Novak: "Hyper-links allow ... [a]ny space [to] have portals to any number of other spaces; location is diminished in importance and non-linear narrative is the natural form. Narratives that may have been achieved through the natural navigation of space-facilitated by walls, doors, hallways, and stairs - must now be deliberately programmed."

Programming here has a tripled sense-what we experience on a network, the underlying coding which creates networked representations, and the traditional architectural program. Over a decade ago, writing in the days before the web, I contrasted the dry form of exploratory hypertext with more liquid constructive hypertexts which create "a version of what it is becoming, a structure for what does not yet exist" (OfTwo Minds 42). In structures which do not yet exist our mortality becomes memory and history and we are the story. The architecture of cyberspace gives form to deliberately programmed non-linear spaces which engender stories we may embody.

My web fiction, Twelve Blue, meant to (trans)form memory and history into and through patterns of interlocking, multiple, and recurrent surfaces along and within a river in a way not unlike the now familiar, insistently programmed spatial lamellae of Frank Gehry. In lieu of proprioceptive depth Twelve Blue subverts the most awkward and insistent programmatic elements of web architecture, frames and hyperlinks, into unstable elements whose behavior drags them back toward a more liquid narrative architecture.

Houses stand as markers of drowning time in this fiction. The central house is imperfectly balanced, flowing between inward as outward, a Moebius space. The drift of a drowning deaf boy whose sinking and eventual rising again constitute the spatio-temporal span of the story is charted from the house by a doctor and her daughter who live at the mouth where the estuary meets a river.

She looked out on the creek and measured out the threads like the fates, silk thread in twelve shades of blue. The trimmings she saved and cast out on the water like pollen, all the pretty colors. They would sink like barren nymphs for the fish to bump with fleshy lips, float for birds to pluck away and decorate the muddy basket of a nest. She had taught herself abandon, taught herself to understand that they were not minor characters, she and her daughter, but at the center of something flowing through them.

Such radiations themselves are rhymed and commemorated in the actual strands of the interface which form the story frame (and frame stories). These threads are meant to create a kind of score in the double sense of music or decorative mark. Parallel narratives are represented by twelve also mostly parallel but sometimes converging or crossing threads whose narratives veer nearer to each other when they do. As a temporal field the twelve lines stand for months but also characters or pairings of them as well. Eight different strips torn from a title screen banner 
constitute these frame elements.

Each surface twists back upon itself like Ben van Berkel and Caroline Bos's Moebius House, where "as the loop turns inside out the materialization follows these changeovers."

Changeovers create for us what Peter M. Canning in a Deleuzian meditation terms "Fluidentity," which he suggests requires "a logic and practice of redoubling (the paradox) in order to break loose ... and open time enough to get through" (35). As the stories take place and intermingle there is inevitably a derangement of expected orders which create what the narratologist Gérard Genette characterizes as syllepses, i.e. "anachronic groupings governed by one or another kinship (spatial, temporal or other)" (85).

Anachronic groupings likewise give form to my fiction "On the Birthday of the Stranger," where again awkward and insistent programmatic elements of both web architecture and narrativity are subverted to evoke liquidity. A generic stranger celebrates his birth in a progression of twenty nine spaces through an actual, albeit composite, European cityscape accessed through a generic grey map of a perhaps island city dotted with 29 red "pinpoints" marking loosely connected narrative episodes. ("Plot," says Koolhaas in one of the lexicon definitions which string through his and Bruce Mau's text like a stranger's footsteps, is "[e]ating oysters with boxing gloves, naked, on the $n$th floor-such is the 'plot' of the 20th century in action" [1034].) This stranger's footsteps and the pinpoints are (re)marked by each of the 29 linked words in a series of enigmatic poetic texts (e.g. "Each of the rows in the garden turned slowly toward another as I planted it, until they looped like worms, all rhythm and curve under your crazy blue eye").

These linked poetic texts are seemingly disconnected to the longer texts of the episodes. Memory and history are unnaturalized here as well, each episode in some sense merely an extended caption for an enigmatic accompanying black and white image, some of which are, however, displaced by the kodacolor dreams of serverpushed, meta-refreshed color images.

The displacement of image by text and vice versa is the strategy and topography of my last hyperfiction, The Sonatas of Saint Francis, undertaken in collaboration with Matt Hanlon, Andrea Morris, and Carolyn Guyer. Sonatas takes place on an island inhabited by several historical characters (St. Francis; William Wordsworth and his sister Dorothy - in this fiction they are conjoined or "Siamese" twins; the engraver and book illustrator Bernard Picart; the poet Lorca; Blake's wife, Catherine Boucher; and Bonnard's mistress, the painter Renee Monchaty) and a number of locals.

Sonatas means to be a novel about the relationships between word and image and the slippages as each lapse into each other. Parts of it are in a local pidgen of the island, which occurring as typos are unreadable or at least obscured visions, i.e. typographically constructed images of what they mean to name, and thus are thought to be sacred in this place, i.e. divine inspiration, the devolution of logo into imago.

In Sonatas an avatar of Picart, a homeless Montreal vernacular artist named Bernie, creates a huge installation in a squat described by the art historian Frankie (himself an avatar of St. Francis) as 
a narrow and airless room in which the smells of must and lacquer and the unmistakable hay and dust fragrance of old paper mix with the saddle and pony perfume of the leather bindings ripped from their volumes and turned now to a waist-high wainscoting of geometric diamonds ....

Exquisite etchings of illustrated volumes plucked from book stalls along StDenis are overlaid with scraps from old rotogravure pages, glossy segments of pages from hardcore porn whose anatomical significance follows behind the immediacy of their innocence and strangeness, and among them like gargoyles or the leering herukas, the wrathful deities of the Tibetan Book of the Dead, are marred Disney characters, palimpsests gouged from the layers below their eyes or breasts or groins ....

The room itself, the Palace, is bookended by ruin, the piss-smelling rooming house now largely uninhabited, the top two floors in fact tinned up, the lobby ceiling falling in at a spot near the wrought iron stairwell, a huge amorphous waterstain draping greenly from the gaping plaster and exposed lath as if a headless lotus plant, its blossom gone or perhaps never having formed.

As we veer more and more toward the virtual, the unseen unscene of the play of our unplayed actual actions, it is more and more our lot to occupy spaces gone before they have actually ever formed. We always look through layers, as if not just the world but our actual vision (itself increasingly overlaid with media projections) were a palimpsest. We become virtual archeologists of actual spaces, exfoliating an endlessly regenerating set of surfaces and volumes alike.

Stefan Schemat is a psychologist and an electronic artist from Hamburg who has created something of an audio guide to the universe called Augmented Reality Fiction (ARF), a Buck Rogers ensemble of contraptions consisting of a mini-computer worn at the belt and a stylishly matching mini GPS dish worn like a dark parrot upon a shoulder.

Schemat's complex authoring system makes it possible to manipulate several "voices" (from twice the four quarters plus one "inner" voice) which can pour forth readings and other sounds that shift according to the fix fed to the computer by the dish. "Walking sounds" mapped upon a city space can wander off ahead, speeding up, slowing down, or lifting off in the most convincing fashion, making the world a radio drama and overlaying it with the possibilities of narrative, thus the augmented part of ARF.

In 1998 I collaborated with Schemat and others on a piece, which garnered honorable mention at Ars Electronica, titled Alexanderplatz 5.0 (Döblin's novel being version 2.0 of version 1.0 , the "real" place, while an early radio play was version 3.0 and Fassbinder's TV mini-series was version 4.0).

My contribution was a little Hörspiel based on the real-life misfortunes of the writer named (I swear this is true) Michael Joyce, whose story, "Vielleicht ein Traum," was published in the Frankfurter Zeitung on July 19, 1931 under the name James Joyce, leading the latter to threaten a lawsuit upon my previous namesake, the Zeitung, and the translator named (I swear this is true) Kafka.

The events of September 2001 made the prospect of a GPS based interactive public art work situated in a New York City landmark locale unlikely, especially one whose scenario involves stories of people leaping from high windows of a flaming 
building, so another collaboration with Schemat has at least been put on hold if not cancelled outright. In that project I had been collaborating with architectural historian and theorist Nicholas Adams, multimedia artist and DJ Herr Colin HoughTrapp, sound artist and anthropologist Tom Porcello, and Schemat to create another ARF, "Triangular voices," set in Washington Square Park in New York. In "Triangular voices," the square would be continuously reimagined as an urban mix, a liquid medium of sound waves wherein urban space and data space surge in an interwoven vortex of sounds. Architectural and cultural spaces as well as the history of the square were to be embodied by the voices of passing figures, from Henry James to present-day junkies to Crystal Eastman, Vassar graduate and a blueblood among the village reds.

Besides the wandering voices and ambient mix of the spatio-temporal cityscape, we anticipated creating particularly dense concentrations of intersecting and interwoven sounds signaled by either recurring audio icons, an urban equivalent of chutes and ladders where a participant can descend into the flow and layered caverns of history or ascend to the overviews and dove-like vistas of holy spirits.

The proposed fiction took its name partly from the triangulation of the satellite, viewer, and actual space, which gives voice to history. Yet the title was also meant to commemorate other lost voices which we triangulate as locales for memory, giving voice to the future. Triangular voices include the dead of the potters field which lay below the square, the muffled voice of the brook which still flows buried beneath it, and most of all the screaming victims of the fire in the Triangle Shirtwaist building which once bordered it .

On the sidewalks there many years ago a garden of dead seamstresses was laid out in a makeshift morgue, black faces like masks, their long skirts like scorched geraniums upon the pavement. It is too much to say that in our proposed work we had hoped to raise them up once again, to build a crystal palace wherein they would twirl like disembodied dancers, a pyramidic and virtual botanical garden, a liquid architecture in which the past would flow like a lost brook through the looking glass space of the (ever) present computer screen.

Yet even if this project is postponed or itself lost, its fundamental energy is reified by recent history. How will we remember among the fragments, in fragments? How can we turn back toward the world we turn our back to in anger and grief? How can we not?

In this regard I am taken by the reflections of my friend and would-be collaborator in this project, Nick Adams, who suggested to his architectural history students in a recent lecture that "in the weeks since September 11 th I have had occasion to rethink my sense of the singularity of that day, and think now that to emphasize the singularity of the moment is a form of self-indulgence, one that undermines our ability to act effectively in the world."

In the place of such self-indulgent singularity Adams suggests a multiplicity that belies the dull drone of the self-indulgent slogan "United We Stand" plastered on shopping bags, automobile bumpers, and frayed flags fastened to helpless and angry cars prowling empty American streets.

"If we look at it properly," Adams says, "art and architecture offer us the 
chance to think beyond the place we now inhabit, the dull walls, the slovenly design of our streets and cut-rate strip malls. In the face of the knife-edge along which we are all inching, day by day, week by week, month by month, and year by year, architecture offers us the chance to think our way out of the place we are in into another world."

Café and cul-de-sac are locales for thinking our way into another world, which is to say another body. What Adams describes is, of course, no less than an exoskeletal storytelling, the embodied stories we tell each other in our lives as we, in his words, "take up our burden in two hands and move it forward deliberately."

Café and cul-de-sac take the inside of the city out and the outside of the city in, respectively. They are symmetrical and even complementary eddies in the flow of our lives. United we stand has ever been a lie; those things stand best and longest which are multiple and even contradictory.

In The Arcades Project Benjamin characterizes the city as "the dwelling place of the collective" where occupied space splits into "dialectical poles" and opens up to the flâneur "as a landscape even as it closes around him as a room." There, according to Benjamin, "the collective is an eternally wakeful, eternally agitated being that-in the space between the building fronts-lives, experiences, understands, and invents as much as individuals do within the privacy of their four walls .... More than any where else, the street reveals itself in the arcade as the furnished and familiar interior of the masses" (423).

The space between the building fronts mark what Molly Nesbit, in speaking of Chris Marker's Sans Soleil, calls "sights that slip, part held, part lost." The interstitial vista is the link which turns the city to a film of memory. "How did humans remember," Marker asks in Sans Soleil, "before they taped, filmed, photographed?"

We might argue that they did so by retracing steps, the characteristic experience of the hypertext, café, and cul-de-sac alike. "There is something revelatory" about retracing steps, Lucy Lippard writes, "each detail is constantly renewed by changing light, seasons, personal moods ... until that specificity doubles back into generality, then back, and forth, with the rhythms of walking, day after day" (125).

These interstitial energies — of specificity doubled back and forth into generality, of the space between the building fronts - summon something like the signifying energy of the collective that Mumford evokes in his famous image of the city as magnet (9).

Mumford argues that "with the magnet we associate the existence of a "field' and the possibility of action at a distance, visible in the 'lines of social force,' which draw to the center particles of a different nature" (82-83). Those lines form for him the "glyphs, ideograms, and script," along with "abstractions of number and verbal signs," which contribute to the pliable notion of city as container contained in its own inscription, a constantly renewing space of memory and our own making (97).

It is this that I see as I look back in passing, a memory of our making, like the hyperfiction perhaps, or the scrap of a lost story of the future once curled like a foetus within the shell shaped womb of the fortune cookie and now flown away like a bright angel formed of ash. 


\section{Works Cited}

Adams, Nick. "War Time." Vassar College, Poughkeepsie, NY. Dec. 2001.

Agamben, Giorgio. The Coming Community. Trans. Michael Hardt. Minneapolis: University of Minnesota Press, 1993.

Benjamin, Walter. The Arcades Project. Trans. Howard Eiland and Kevin McLaughlin. Cambridge: Belknap Press, 1999.

Byrne, David, dir. True Stories. Warner Bros, 1986.

Canning, Peter M. "Fluidentity." SubStance 44 (1984): 34-45.

de Certeau, Michel. The Practice of Everyday Life. Trans. Steven Randall. Berkeley: University of California Press, 1983.

Debord, Guy. Society of the Spectacle. Detroit: Black and Red, 1977.

Frank, Joseph. "Spatial Form in Modern Literature." Sewanee Review 53 (1945): 221-240, 456, 643-653.

Genette, Gérard. Narrative Discourse: An Essay in Method. Trans. Jane E. Lewin. Ithaca: Cornell University Press, 1980.

Joyce, Michael. "On the Birthday of the Stranger." Evergreen Review 102 (1999) <http:/ /www.evergreenreview.com/102/evexcite/joyce/nojoyce.html>.

—. Twelve Blue. $1997<\mathrm{http}: / /$ www.eastgate.com/TwelveBlue.html>.

-. Of Two Minds: Hypertext Pedagogy and Poetics. Ann Arbor: University of Michigan Press, 1995.

Joyce, Michael, et al. The Sonatas of Saint Francis. $2000<\mathrm{http}: / /$ supertart.com/sonatas/ index.html>.

Koolhaas, Rem, Bruce Mau, and Office for Metropolitan Architecture. S, M, L, XL. Ed. Jennifer Sigler. New York: Monacelli Press, 1998.

Lippard, Lucy. Overlay. New York: Pantheon Books, 1983.

Loudon, Annette. "Exploding the Temple." $1998<$ http://flotsam.detritus.net/Ezone/ez/ e14/articles/loudon/temple.html>.

Lynn, Greg. "Blobs.” Journal of Philosophy and the Visual Arts 6 (1995): 39-44.

—. "Greg Lynn: An Advanced Form of Movement." Architectural Design 67 (May/June 1997): 54-55.

Lynn, Greg, et al. H2 House m.FORM. $1999<$ http://www.basilisk.com/mFORM/website/ m.FORM.html>.

Lunenfeld, Peter. "Permanent Present." art/text 63 (November 1998-January 1999) <http:/ /architettura.supereva.it/extended/19990201/index_en.htm>.

Marker, Chris. La Jetée. Argos Films, 1962.

—. Sans Soleil. Argos Films, 1982.

Massumi, Brian. "Interface and Active Space, Human-Machine Design." Proceedings of the Sixth International Symposium on Electronic Art. $1995<\mathrm{http} / / / \mathrm{www} . \mathrm{anu} . \mathrm{edu} . \mathrm{au} / \mathrm{HRC} /$ first_and_last/works/interface.htm>.

Mork, Knut. "Interview with Marcos Novak." 1995 <http://www.altx.com/interviews/ marcos.novak.html>.

Mumford, Lewis. The City in History: Its Origins, Its Transformations, and Its Prospects. New York: Harcourt, Brace and World, 1961.

Nesbit, Molly. Communication to the author. 2001.

Novak, Marcos. “TransTerraFirma: After Territory.” 1996 <http://www.sitesarch.org/ MarcoFrl.html>.

Schemat, Stefan, et al. Alexanderplatz 5.0. $1999<\mathrm{http}: / / \mathrm{www} . \mathrm{media}-\mathrm{g} . \mathrm{com} /$ party01.html\#Start>.

Powers, Richard. "Being and Seeming: The Technology of Representation." Context 3 
(2000) <http://www.dalkeyarchive.com/context/no3/powers.html>.

Skagestad, Peter. "Peirce, Virtuality, and Semiotic." The Paideia Project: On-Line Proceedings of the Twentieth World Congress of Philosophy. $1998<\mathrm{http}: / / \mathrm{www} . \mathrm{bu} . \mathrm{edu} / \mathrm{wcp} /$ Papers/Cogn/CognSkag.htm>.

van Berkel, Ben, and Caroline Bos. Moebius House. $1999<\mathrm{http} / /$ www.archilab.org/public/ 1999/artistes/benv0len.htm>. 